\title{
An investigation into the effectiveness of Robert Enright Forgiveness Inventory (EFI) on the marital quality of women affected by infidelity.
}

\author{
Mansour Sodani“, Hadi Gholammohammadi, Reza Khojastehmehr, Zabihollah Abbaspour \\ Department of Counseling \& Guidance, Shahid Chamran University of Ahvaz, Ahvaz, Iran
}

\begin{abstract}
Background: Infidelity is an interpersonal traumatic incident that can have cognitive, emotional and behavioral consequences for the victim. This study aimed to explain the effectiveness of Robert Enright Forgiveness Inventory (EFI) on the marital quality of women affected by infidelity in Ahvaz.

Methods: In this research, a single-case experimental design was used. The population included all women affected by infidelity referring to Ahvaz counseling centers in 2016. The study sample which included 4 women referring to Ahvaz Avaye Daroon Center was selected using available sampling method. The participants responded to the Marital Quality Questionnaire during the treatment and follow-up phases. The data were analyzed using visual analysis, clinical significance (Reliable Change Index and Normative Comparison), and the recovery percentage formula.

Findings: The results indicated that the marital quality increased in women in the treatment (40.37) and (44.88) follow-up phases. According to the normative comparisons, $t$ was bigger than the table with the degree of freedom of 32; therefore, it can be argued that there was no clinical difference between the normal and abused groups in terms of marital quality.

Conclusion: Robert Enright Forgiveness Inventory (EFI) aims to change beliefs, advocate positive thinking, increase the sense of tranquility, reduce the sense of revenge and teach communication skills. These measures can help increase the marital quality of women affected by infidelity.
\end{abstract}

Keywords: Infidelity, Robert Enright forgiveness therapy, Marital quality.

Accepted on April 19, 2019

\section{Introduction}

Marriage is the most important contract in every person's life. People get married for various reasons. In addition to sexual needs, which are prerequisite factors such as love, emotional and financial security, relaxation, and escape from loneliness contribute to marriage [1]. Marriage helps constitute the family. Accordingly, the family essentially provides help, relief, and relaxation. The family is supposed to reduce the pressure on members and help them grow and flourish. If the family provides a healthy and constructive environment for the members and satisfies their physical and mental needs, they may less likely to need the medical institutions [2,3]. Infidelity is one of the factors that endangers the health of the family. It is one of the main causes of divorce and disintegration of the family [4]. Infidelity is a shocking issue for couples and families, and a common phenomenon for family therapists $[5,6]$. Infidelity is a violation of a couple's assumed or stated contract regarding emotional or sexual exclusivity [7]. The institution of marriage is integral to the existence of the family. We believe that marriage is a social as well as personal good, contributing to the health and happiness of both spouses and their children. Scientific evidence from a variety of fields as well as human experience have shown that any deviation from this norm is harmful, even if sometimes unpreventable as in the case of death. It is still more harmful when this variation challenges the institution of marriage itself, as in the cases of same-sex unions and casual divorce.

According to Gordon [8], infidelity has adverse and unpleasant side effects and causes stress, shock, anger, depression, sadness, loss of self-esteem, and so on. Infidelity can be manifested on a large scale and cause irreparable damages for the couples affected by it. Regarding the cognitive dimensions, infidelity can lead to rumination, depression and negative thoughts. Meanwhile, it may also lead to anger, annoyance, low self-esteem and low self-confidence. It may also have behavioral consequences such as aggression, retaliation or physical aggression [9]. The adverse complications mentioned above can affect the quality of life of couples. The World Health Organization (WHO) defines the quality of life as the personal perceptions of individuals about their place in life, given the cultural values that individuals live with and follow their goals, expectations and standards of living [10]. One of the essential components of quality of life is the concept of marital quality. Marital quality can be considered as a psychological state, which is not created spontaneously. The couples need to work together in order to enhance this quality. Particularly in the early years, marital quality is extremely unstable, being exposed to the highest risk. Accordingly, the 
divorce rate suggests that the quality of life of couples is not easily predictable [10]. Research indicates that poor marital quality is one of the predictors of infidelity [11]. In some studies, marital commitment has been considered as one of the indicators of marital quality [12].

Accordingly, marital quality can be regarded as the successful performance of a marriage, which is the result of various factors such as couples' reconciliation and commitment to one another. It is also one of the most important predictors of a stable marriage [13]. The findings suggest that couples affected by infidelity can be helped in several ways [5,14]. Experts argue that infidelity is different from other problems couples face and requires special attention in terms of therapeutic strategies [9]. Given the fact many studies that have been conducted on infidelity [15], therapists state that they have no model for addressing this problem. Given the complex nature of the infidelity and its disastrous effects on couples, effective interventions are needed to help couples. Various theoretical models have been presented to explain and treat couples suffering from infidelity problems, including Emotional Focused Therapy (EFT), Forgiveness Therapy, CognitiveBehavioural Therapy, Traumatic Model and Ritual Model. Robert Enright Forgiveness Inventory (EFI) is one of the approaches used to control and treat infidelity reactions [14]. The Enright Forgiveness Inventory (EFI) is an objective measure of the degree to which one person forgives another who has hurt him or her deeply and unfairly. The EFI has sixty items and three subscales of twenty items each that assess the domains of affect, behavior and cognition toward the offending other. The manual provides administration and scoring instructions, the establishment of validity and internal consistency, national and international norm tables, and a bibliography of forgiveness research articles. The manual also presents evidence of the association between high scores on the EFI and low scores on measures of anxiety (STAI) and depression (BDI).

There has been growing research on the forgiveness in the past decade due to the shift in focus from treatment to personal growth. This positive shift has attracted the attention of scientists and the general public, since it focuses on positive emotions such as hope, appreciation, wonder and joy, using a distinctive language [14]. Forgiveness can be a barrier to the negative effects such as stress and negative emotions [16]. Forgiveness expands the cognitive and behavioural framework of individuals and creates new adaptive techniques for them. Forgiveness can also be considered as an interpersonal process in relationships. As initial focus of psychological research on the issue of forgiveness, researchers investigated the victims who chose to forgive the abusers of the offense [14].

Forgiveness enables a person to maintain and retrieve relationships in times of conflict. Forgiveness is getting rid of negative emotions, cognitions and behaviors such as hostility, revenge, and verbal aggression in response to injustices [9]. Enright Forgiveness Inventory (EFI) has four phases:

- Disclosure

- Decision-making
- Action

- Deepening

In the disclosure phase, issues such as psychological defences, exposing anger, accepting anger, knowledge of the cognitive review, guilt, insights into the people affected and insights about the future are examined. In the decision-making phase, issues such as insight into the old strategies, considering the forgiveness as an option and forgiving the abuser are investigated. The third phase deals with re-framing, empathy and acceptance of pain and suffering. In the deepening phase, issues such as finding the meaning of life, the need to forgive others and general support are investigated [17].

Research suggests the impact of Enright Forgiveness Inventory (EFI) on various issues of life. Decaporale et al. [17] highlighted the impact of this approach on the quality of life of middle-aged Italian women. Moreover, this approach can effectively reduce depression, anxiety and improve the interpersonal relationships of couples [14]. However, few researches have been carried out on the issues of the infidelity. Forgiveness approaches have been the focus of research in the past. Recent studies indicate that forgiveness is a psychological construct and a therapeutic approach to deal with communication problems and conflicts between the married couples. Couples who forgive each other's mistakes will experience higher satisfaction and commitment. In addition, forgiving our own and other's mistakes will reduce stress, blame-casting, hostile behavior, and aggression in interpersonal relations. Hence, people will experience more compatibility and healthier relationships. Emphasizing it as a trait for the believers, Islamic literature refers to forgiveness as a therapy as well. Forgiveness therapy is one of the approaches used in the field of controlling and treating the responses to marital infidelity.

\section{Methods}

In this research, a single-case experimental design was used. The population included all women affected by infidelity referring to Ahvaz counseling centers in 2016. The participants entered the baseline phase and then received the 8 sessions of treatment and follow-up, which lasted two months. The study sample which included 4 women referring to Ahvaz Avaye Daroon Center was selected using available sampling method. The participants responded to the Marital Quality Questionnaire during the treatment and follow-up phases. The inclusion criteria included elementary education, willingness to cooperate for receiving counseling intervention, at least one year of marriage, expressing remorse, requesting forgiveness, and psychological health. In contrast, the exclusion criteria included personality disorders, paranoid states, definitive decision for divorce and infidelity. The data were analysed using visual analysis, clinical significance (Reliable Change Index and Normative Comparison), and the recovery percentage formula.

The treatment protocol briefly included the following sessions: 


\section{Session 1}

Familiarity with the basic principles of the group, including constructive interaction of members; expressing feelings of security and trust; providing feedback and creating an unbiased atmosphere.

Objective: To facilitate the communication of the members and to create a secure environment.

\section{Session 2}

The person affected by infidelity uses defence mechanisms against pain. Therapeutic strategies: Examining psychological defences; facing the anger; accepting anger.

Objective: To reveal the suffering and communicate with it.

\section{Session 3}

The person affected by infidelity compares himself with the abuser of the offense, feels injustice and constantly reviews his suffering. Therapeutic Strategies: Awareness of mental efficacy; awareness of cognitive review of the guilt; an insight into the comparison between the person affected by the infidelity and the abuser.

Objective: To reveal the suffering and communicate with it.

\section{Session 4}

The person affected by infidelity compares himself with the abuser of the offense, feels injustice and constantly reviews his suffering. Therapeutic Strategies: Thinking about the results of forgiveness; an insight into changing the attitude that actions have consequences.

Objective: To reveal the suffering and communicate with it.

\section{Session 5}

Decision-making is the second phase in the treatment process. The person affected by infidelity asks for justice and legal persecution. She feels inequality and disappointment. This worsens her negative emotions.

Therapeutic strategies: an insight into the fact that old strategies do not work well; considering forgiveness as an option; and trying to forgive the person who has committed infidelity.

Objective: Trying to forgive the person who has committed infidelity.

\section{Session 6}

The person affected by infidelity is saddened by the fact that she has hostile feelings for the abuser, and she is keen to use forgiveness as an option. But she still thinks that she could be affected by wrong decisions.

Therapeutic strategies: empathy with an abuser.

Objective: Forgiving the abuser.

\section{Session 7}

The person affected by infidelity is saddened by the fact that she has hostile feelings for the abuser, and she is keen to use forgiveness as an option. But she still thinks that she could be affected by wrong decisions.

\section{Therapeutic strategies:}

Objective:

\section{Session 8}

This the fourth phase in the treatment process. It allows the sufferer to find a new meaning for her and others.

Therapeutic Strategies: Finding meaning for yourself and others; knowing that you have made a mistake in the past and needs help; learned from this mistake and setting new goals in life.

Objective: Forgiving the abuser.

\section{Research Tools}

\section{Marriage quality questionnaire}

Developed by Enrigh, in 2012 [18], this scale consists of 14 items. It includes subscales of consensus, satisfaction, showing the marital quality score of the individual. Fairclough in 2010 [19] reported that the reliability of the questionnaire for consensus, satisfaction and cohesion was $0.79,0.80$, and 0.90 respectively. In Iran, this scale was examined by Nasser in 2011 [20] and the coefficients of internal consistency reliability including Cronbach's alpha were examined. Accordingly, the validity coefficients of marital quality and consensus were respectively $0.39,0.36$ and 0.33 respectively. This was significant at the $\mathrm{P} \leq 0.0001$. In this research, 50 subjects completed the questionnaire and the Cronbach's alpha coefficient was 0.67 .

\section{Findings}

Enright Forgiveness Inventory (EFI) improves the marital commitment of women affected by male infidelity.

According to Table 1, the mean marital quality in the baseline phases for the first, second, third and fourth participant was $35.5,29.8,38.3,32.85$ respectively. Accordingly, the mean treatment for the first, second, third and fourth participant was $49.3,44.67,50.33$ and 46.33 respectively. The values obtained in the follow-up phase for the first, second, third and fourth participant was $51,45.5,52.5$ and 48 respectively. The marital quality increased in the treatment phase for the first, second, third and fourth participant up to $38.87,43.66,49.9$ and 52.68, respectively. Meanwhile, the marital quality increased in the follow-up phase for the first, second, third and fourth participant up to $31.41,37.07$, and 41.03 and 46.12 respectively. The second and the third participant had highest and the least change, respectively. The reliable change index in the treatment phase for the first, second, third and fourth participant was $2.42,2.6,2.11$ and 2.36 respectively $(Z=1.96)$. 
Meanwhile, reliable change index in the follow-up phase for the first, second, third and fourth participant was 2.71, 2.74, 2.48 and 2.65 respectively $(\mathrm{Z}=1.96)(\mathrm{P}<0.05)$. Therefore, the findings indicated that Enright Forgiveness Inventory (EFI) could improve the marital quality, especially in the second participant.

Table 1. The effectiveness of Enright Forgiveness Inventory (EFI) on marital quality Forgiveness.

\begin{tabular}{|c|c|c|c|c|}
\hline \multicolumn{5}{|c|}{ Enright Forgiveness Therapy } \\
\hline Treatment phases & 1st participant & 2nd participants & 3rd participants & 4th participants \\
\hline 1st baseline & 36 & 31 & 39 & 33 \\
\hline 2nd baseline & 35 & 30 & 38 & 33 \\
\hline 3rd baseline & 35 & 30 & 39 & 32 \\
\hline 4th baseline & 36 & 29 & 39 & 32 \\
\hline 5th baseline & & 29 & 37 & 34 \\
\hline 6th baseline & & & 38 & 33 \\
\hline 7th baseline & & & & 33 \\
\hline Mean baseline phases & 35.5 & 29.8 & 38.3 & 32.85 \\
\hline \multicolumn{5}{|c|}{ Treatment } \\
\hline Session 3 & 42 & 38 & 45 & 40 \\
\hline Session 6 & 49 & 45 & 51 & 46 \\
\hline Session 8 & 57 & 51 & 55 & 53 \\
\hline Mean treatment phases & 49.3 & 44.67 & 50.33 & 46.33 \\
\hline Reliable change index & 2.42 & 2.6 & 2.11 & 2.36 \\
\hline Post-treatment marital quality improvement & $38.87 \%$ & $49.90 \%$ & $31.41 \%$ & $41.03 \%$ \\
\hline Total post-treatment recovery & $40.37 \%$ & & & \\
\hline \multicolumn{5}{|c|}{ Follow-up } \\
\hline 1st follow-up & 51 & 45 & 52 & 47 \\
\hline 2nd follow-up & 51 & 46 & 53 & 49 \\
\hline Mean follow-up & 51 & 45.5 & 52.5 & 48 \\
\hline Reliable change index & 2.71 & 2.74 & 2.48 & 1.65 \\
\hline Post-follow-up recovery rate & $43.66 \%$ & $52.67 \%$ & $37.07 \%$ & $46.12 \%$ \\
\hline Total post-follow-up recovery rate & $44.88 \%$ & & & \\
\hline
\end{tabular}

According to Figure 1, the mean scores of the four participants increased in the treatment phase compared to the baseline phase. Given the Enright Forgiveness Therapy, it was anticipated that changes would be positive for all participants in terms of the marital quality.

The normative comparison formula was used to examine the difference between the mean of the normal group and the abused groups.
It should be noted that the mean (standard deviation) of the normal and the abused groups was 50.64 (10.24) and 47.65 (2.61), respectively. The number of participants in the normal and the abused groups was 30 and 4, respectively. Accordingly, the degree of freedom was $\mathrm{df}=\mathrm{n} 1+\mathrm{n} 2-2=32$. 
An investigation into the effectiveness of Robert Enright Forgiveness Inventory (EFI) on the marital quality of women affected by infidelity
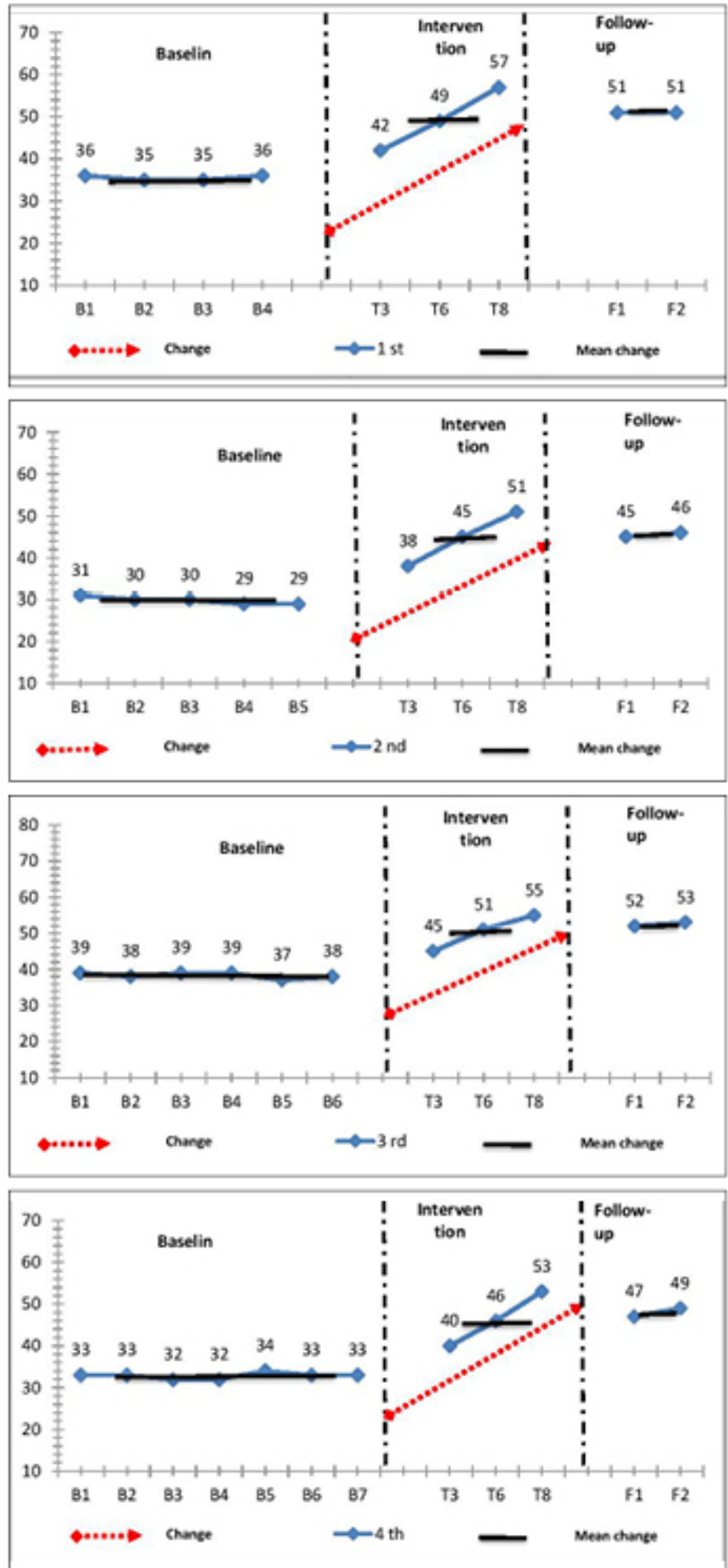

Figure 1. The scores of the four participants in the baseline, treatment and follow-up phases. 
$C \cdot E^{t}(d f)=\left(\frac{\left({ }_{N}-M_{C}-\delta_{1}\right.}{S E_{(N-C)}}\right)$

$S E_{N-C}=\left\{\left[\frac{\left(n_{N}-1\right) S D_{N}^{2}+\left(n_{C}-1\right) S D_{C}^{2}}{n_{N}+n_{C}-2}\right]\left[\frac{1}{n_{N}}+\frac{1}{n_{C}}\right]\right\}^{\frac{1}{2}}$

$S E_{N-C}=\left\{\left[\frac{(30-1)(10.24)^{2}+(4-1)(2.61)^{2}}{30+3-2}\right]\left[\frac{1}{30}+\frac{1}{4}\right]\right\}^{\frac{1}{2}}$

$t_{(32)}=\frac{50.64-47.65-(-10.24)}{5.17}$

$t_{(32)}=2.56>t$

According to the results, $\mathrm{t}$ was bigger than the table with a degree of freedom of 32 . Therefore, it can be argued that there was no clinical difference between the two groups in terms of marital quality.

$\operatorname{trad}_{(d f)}=\left(\frac{M_{N}-M_{C}}{S E_{N-C}}\right)$

$t_{(32)}=\frac{50.64-47.65}{5.17}=0.58$

$t_{(32)}=0.58<t$

According to the results, there was no significant difference between the abused and normal women in terms of marital quality and the Enright Forgiveness Inventory (EFI)was effective (Null hypothesis: The mean of the treated and normal group was identical) (Table 2).

Table 2. The classification of the results of statistical significance tests for the marital quality variable.

\begin{tabular}{lll}
\hline \multicolumn{2}{c}{ Significance test } \\
\hline Variables & Significant effect & $\begin{array}{l}\text { Non-significant } \\
\text { effect }\end{array}$ \\
\hline \multirow{2}{*}{ Significant } & 1 & 2 \\
\cline { 2 - 3 } & Statistically different, clinically identical & Clinically identical \\
\hline $\begin{array}{l}\text { Not } \\
\text { significant }\end{array}$ & 3 & 4 \\
\cline { 2 - 3 } & Clinically different & Ambiguous findings \\
\hline
\end{tabular}

According to the results, there was no significant difference between the abused and normal participants in terms of marital quality variable. In 2006, Harris [21] argued that row number two (clinically identical) was better than other rows, since it can be predicted that the group undergoing treatment returned to the normal range (Figure 2).

As shown in the diagram above, the Enright Forgiveness Inventory (EFI) could put people in normal range after treatment or intervention. In other words, the abused participants with a mean (score of 47.65) could obtain 40.4 in the normal spectrum. Therefore, Enright Forgiveness Inventory (EFI) could increase the marital quality of the participants.

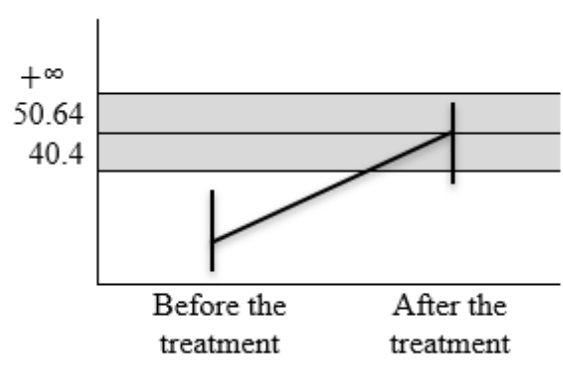

Figure 2. Enright forgiveness inventory range (Before and after the treatment).

\section{Discussion}

Good marriage is one of the important factors affecting the mental health of the community. If marriage fails to provide a favourable condition for fulfilling the psychological needs of the couples, not only mental health cannot be realized, but also can have negative and irreparable consequences for the couples. Accordingly, neurological disorders, depression and suicide are some of the major consequences. Infidelity can affect many psychiatric disorders, including physical, cognitive and behavioural disorders [22]. Infidelity increases marital conflicts and reduces the marital quality. Therefore, it is necessary to find a solution for infidelity. There are many approaches to for treating the infidelity, one of which is the Enright Forgiveness Therapy.

The present study investigated the effectiveness of Enright Forgiveness Inventory (EFI)in improving the marital quality of women affected by infidelity. According to the results (Reliable Change Index and Normative Comparison), the Enright Forgiveness Inventory (EFI) could increase the marital quality of women participating. Haj Alizadeh et al. [23] concluded that forgiveness plays an important role in promoting the happiness and positive thinking of divorced women. Azarhoosh et al. [24] argued that forgiveness therapy can increase hope as an effective intervention. Movahedi et al. [2] concluded that forgiveness therapy reduced marital conflicts and increased the quality of life of women.

In 2017, Taherian and Rajaei [25] highlighted the effectiveness of forgiveness therapy on marital satisfaction of the couples. Hamidipour 2010, [26] found that Enright Forgiveness Inventory (EFI) could increase the marital satisfaction of couples. Decaporale et al. [17], highlighted the effectiveness of Enright Forgiveness Inventory (EFI) on the quality of life of women [14]. Khorramabadi [14] investigated the effectiveness of Enright Forgiveness Inventory (EFI) on the satisfaction and quality of couples. They argued that forgiveness serves as a moderator mechanism and improves the marital quality [27-32].

According to Decaporale et al. [17], the woman affected by infidelity initially attempts to escape from the pain and suffering using her own defence mechanisms and tries reviewing that incident over and over again in her mind. Finally, her view of global justice undergoes a significant change. According to Mohammadi et al. [33], women find it 
very difficult to forgive their spouse at first since they regard this as reconciliation. They argue that their spouse deserves punishment and should escape it. However, forgiveness is different from reconciliation. Forgiveness is an internal process that helps women forgive their spouse and forget all about punishment. Correcting this misconception can accelerate the process of forgiveness. The individuals are helped to create new insights into the marital conflicts, suffering and discomfort. This change in beliefs and beliefs can change the individuals' behaviour. According to the cognitive behavioural, cognitive and rational-emotional cognitive therapies, our thoughts and insights can affect our behaviours. In other words, in these approaches, therapists seek to substitute rational thoughts with irrational thoughts [34,35].

According to Decaporale et al. [17], the individual seeks a solution and attempts to deal with the pain and suffering. According to Turkamani et al. [31], forgiveness prevents the suppression of aggression or anger and releases the negative emotions [31]. The person affected by infidelity decides to forgive the spouse. By reducing negative emotions and increasing positive emotions, forgiveness can help the women develop a new perspective. In other words, the person affected by infidelity gradually finds meaning for her suffering and concludes that she is not the only one involved with this issue [17]. At this phase, it can be argued that forgiveness strengthens the marital relationship and commitment [36]. In other words, a change of attitude helps the person rebuild trust and commitment, increasing the marital quality [4]. According to the Enright Forgiveness Therapy, the person affected by infidelity happens to realize the strengths of the abuser. This can result in a positive attitude, facilitating the process of forgiveness. The acceptance helps the person better accept those thoughts, rather than to avoid the problem and fight negative thoughts. By accepting the issues, negative emotions lose their power [32]. In addition to facilitating the process of forgiveness, positive attitudes can increase the marital quality and psychological well-being of the individual [37]. Positive attitudes are one of the predictors of life satisfaction [38].

\section{Conclusion}

Enright Forgiveness Inventory (EFI) is capable of changing beliefs, developing positive thinking, increasing sense of tranquillity, reducing the sense of revenge, teaching communicative skills and improving the marital quality of women affected by male infidelity.

\section{Conflict of Interests}

The authors did not report any conflicts of interests in this research.

\section{Acknowledgement}

We need to express our gratitude to the Avaye Daroon Consulting center in Ahvaz for their cooperation during this research. We are also grateful for all the people who supported the author.

\section{References}

1. Harris AH, Luskin F, Norman SB, Stander DS, Bruning J, Evans S, Thoresen C. Effects of group forgiveness intervention on forgiveness, perceived stress and traitanger. J Clin Psychol 2006; 62: 715-733.

2. Movahedi A, Hosseini HM, Zargham, M. Forgiveness therapy: A tool for marital conflict and quality of life. Third international conference on psychology, education and lifestyle. Torbat Heydarieh Azad University.

3. Gerhini MK, Erghini ZK. the effectiveness of teaching positive thinking skills on marital satisfaction. Third scientific and research congress on the development and promotion of educational sciences and psychology, sociology and social cultural sciences of Iran, Tehran, Scientific society for the promotion and development of basic sciences and techniques.

4. Case B. Healing the wounds of in fidelity through the healing power of apology and forgiveness. J Cou Rel Ther 2005; 4:41-54.

5. Gordon KC, Baucom DH, Snyder DK. An integrative intervention for promoting recovery from extramarital affairs. J Mar Fam Ther 2007; 30:213-231.

6. Honarparvaran. The effectiveness ACT on the women affected by male infidelity. Quarterly Journal of Women and Society 2014; 5:135-150.

7. Drigotas S, Barta W. The cheating heart: Scientific exploration of infidelity. Cur Dire in Psyc Sc 2001; 10:177-180.

8. Gordon K, Baucom DH, Synder DK. Treating couples recovering from infidelity: An integrative approach. J Clin psychol 2005; 61: 1393-405.

9. Glass SP, Wright TL. Reconstructing marriages after the trauma of infidelity in: Clinical handbook of marriage and couples' interventions. New York, NY: John Wiley \& Sons, USA. 1997; 471-507.

10. Qorbani. the relationship between mental health and the quality of children. Journal of Refahe Ejtemaei 2010; 18:55-77.

11. Cheraghi AS. The relationship between excitement and quality of marital relationship and the marital infidelity. International Conference on New Horizons in Educational Sciences, Psychology and Social Violence. Tehran, Society of Modern Science and Technology.

12. Mills SD. Men and marital commitment (Master's Thesis). Purdue university 2000.

13. Determinants of marital quality in an arranged marriage society. Soc Sci Res 2013; 42:59-70.

14. Khorramabadi H, Khodabakhsh. The effectiveness of group counseling on the restoration of marital relationship after the male infidelity. J Med Ethi 2017; 10:29-36.

15. Javid M, Kazemi M. The effectiveness of forgiveness on the infidelity in married women in Tehran in 2010-2011. Sociol Res 2013; 6:139-155.

16. Mansouri K. The effect of forgiveness in medical and nursing students. Journal of Fought Danesh 2012; 3:45-54. 
17. Decaporale LN, Steffen AM, Marwit S, Meuser TM. Extension of Enright forgiveness inventory to middle-aged and older wives. Journal of Religion, Spirituality and Aging. 2013; 25:344-357.

18. Enrigh RD. The forgiving life: A pathway to overcoming resentment and creating legacy of love. Ame psyc ass 2012.

19. Fairclough DL. Design and analysis of quality of life studies clinical trial. CRC press 2010.

20. Nasser Y. An investigation into the marital quality psychometric scale (RDAS). Quarterly Journal of Clinical Psychology and Consulting 2011; 1:183-200.

21. Harris VW. Context and interaction: A comparison of individuals' actress various income levels. Science context 2006; 17:48-52.

22. Burrell N, Allen M, Gayle BM, Preiss RW. Managing interpersonal conflict: advances through meta-analysis. Routledge Press 2014.

23. Haj Alizadeh K, Salehi A, Arbabi H, Hafezi. The effectiveness of forgiveness therapy on positive thinking and happiness of divorced women. Third conference on psychological findings. Bandar Abbas University 2016.

24. Azarhoosh N, Kimayei SA, Mashhadi. An investigation into the effectiveness of Robert Enright Forgiveness Inventory (EFI) to increase the hope of divorced women. The Booklet on the 9th International Psychiatric Congress of the Asian Summit on Cultural Values. Tehran 2017.

25. Taherian, M, Rajaei MM. The effectiveness of forgiveness therapy on increasing marital satisfaction of women. Third national conference on strategies for the development and promotion of education sciences, psychology, consulting and education in Iran 2017.

26. Hamidipour. An investigation into the effect of group counselling on marital satisfaction. Journal of Psychology and Religion 2010; 3:107-123.

27. Mamalkis PM. Painting a bigger picture: Forgiveness therapy with pre - marital infidelity: A case study, J Fam Psychothe 2001; 12:354-395.

28. Kiana FK. Forgiveness and its role in nurses' caregiving behaviors and mental health. J Med Ethics 2013; 7:11-32.

29. Khayatan. The impact of group counseling on adaptation and quality of life of women referring to Najafabad counseling centers. Knowledge and Research Quarterly in Applied Psychology 2015; 16:34-42.
30. Asgari M, Bajelan L. The effect of forgiveness therapy on marital conflict and life commitment of women in Arak. Scientific J of Consul Rese 2014; 13:118-139.

31. Turkamani PM, Aminpoor M, Bakhtiari SB, Khalili RD. An investigation into the effectiveness of forgiveness on marital conflicts. Zanko Journal of Medical Sciences / Kurdistan University of Medical Sciences 2018; 19:31-45.

32. Dryden V. The Application of Rational Emotional Therapy in Life Skills. Tehran: Arjmand Publication 2014.

33. Mohammadi G. Enriching relationships in Marriage with a religious and cultural approach. Mashhad: Faraangizesh Publications 2016.

34. Dargahi SH, Mohsenzadeh F, Zahrakar K. The effect of teaching positive thinking skills on psychological wellbeing and quality of marital relationship in infertile women. J Posi Psychol 2015; 3:45-57.

35. Mehrabizadeh MN, Shabani AS. The relationship between optimism and social support and satisfaction of life in female students. Journal of Women and Culture 2013; 5:45-57.

36. Backus, Lisa N. Establishing links between desecration, forgiveness and marital quality during pregnancy. Master's thesis Bowling green state university 2009; 79- 82 .

37. Destefano J, Oala M. Extramarital affairs: Basic considerations and essential task in clinical work. TFJ 2008; 16:13-19.

38. Harris R. Acct in simple language, the alphabet of acceptance and commitment-based treatment (Aminzadeh). Tehran Arjmand Publication 2018.

\section{*Correspondance to}

Mansour Sodani

Department of Counseling \& Guidance

Shahid Chamran University of Ahvaz

Ahvaz

Iran 